\title{
Pre-stack inversion for caved carbonate reservoir prediction: A case study from Tarim Basin, China
}

\author{
Zhang Yuanyin', Sam Zandong Sun ${ }^{1 *}$, Yang Haijun², Wang Haiyang ${ }^{1}$, Han \\ Jianfa $^{2}$, Gao Hongliang ${ }^{2}$, Luo Chunshu ${ }^{2}$ and Jing Bing ${ }^{2}$ \\ ${ }^{1}$ Laboratory for Integration of Geology \& Geophysics, China University of Petroleum, Beijing 102249, China; \\ ${ }^{2}$ Research Institute of Exploration \& Development, PetroChina Tarim Oilfield Company, Korla 841000, China \\ (C) China University of Petroleum (Beijing) and Springer-Verlag Berlin Heidelberg 2011
}

\begin{abstract}
The major storage space types in the carbonate reservoir in the Ordovician in the TZ45 area are secondary dissolution caves. For the prediction of caved carbonate reservoir, post-stack methods are commonly used in the oilfield at present since pre-stack inversion is always limited by poor seismic data quality and insufficient logging data. In this paper, based on amplitude preserved seismic data processing and rock-physics analysis, pre-stack inversion is employed to predict the caved carbonate reservoir in TZ45 area by seriously controlling the quality of inversion procedures. These procedures mainly include angle-gather conversion, partial stack, wavelet estimation, low-frequency model building and inversion residual analysis. The amplitude-preserved data processing method can achieve high quality data based on the principle that they are very consistent with the synthetics. Besides, the foundation of pre-stack inversion and reservoir prediction criterion can be established by the connection between reservoir property and seismic reflection through rock-physics analysis. Finally, the inversion result is consistent with drilling wells in most cases. It is concluded that integrated with amplitude-preserved processing and rock-physics, pre-stack inversion can be effectively applied in the caved carbonate reservoir prediction.
\end{abstract}

Key words: Carbonate reservoir prediction, pre-stack inversion, amplitude-preserved processing, rock physics

\section{Introduction}

The carbonate reservoir in Tarim basin is deeply buried (more than 5,000 m). The TZ45 area, which is located in the western segment of the Tazhong-I structural belt in the Tarim Basin, is studied in this paper. Due to the desert surface conditions, the seismic data is usually characterized by weak seismic reflection, serious high-frequency components attenuation, strong coherence noise, low signal-to-noise (S/ $\mathrm{N})$ ratio, and low resolution. Drilling results and former research show that Ordovician carbonate reservoir in the area consists of dissolution caves with different scales (Wu et al, 2005; Zhao et al, 2007; Pang et al, 2010; Yang et al, 2010). Consequently, the prediction key here is how to predict these dissolution caves effectively (Li and Downton, 2000; Chen et al, 2005; Gong et al, 2008; Zhang et al, 2008). Due to the lack of pre-stack data quality control standards and the shortage of $\mathrm{S}$-wave logging data in carbonate formation, post-stack data but not pre-stack data are widely used for reservoir prediction in Tarim Basin at present (Cai, 2005; Yang et al, 2007; Liu et al, 2008; Zeng et al, 2011). Besides, pre-stack inversion

\footnotetext{
* Corresponding author. email: samzdsun@yahoo.com

Received March 18, 2011
}

method for carbonate reservoir prediction is limited by the tough situations in this area.

In this paper, firstly, the methodology and quality-control method of amplitude-preserved processing are introduced. The pre-stack data should be achieved based on the principle that they are consistent well with the synthetics. Subsequently, the foundation of pre-stack inversion and reservoir prediction criterion are established by the connection between reservoir property and seismic reflection through rock-physics analysis. Finally, pre-stack inversion is employed to predict caved carbonate reservoir in the TZ45 area by fine quality-control of inversion procedures. These procedures mainly include anglegather conversion, partial stack, wavelet estimation, lowfrequency model building and inversion residual analysis.

\section{Foundation for pre-stack inversion}

\subsection{Amplitude-preserved processing}

For the seismic data in the TZ45 area, special attentions should be paid to the following aspects: (1) The $\mathrm{S} / \mathrm{N}$ ratio of seismic data is decreased by the desert surface and the primary and secondary interference of various dunes; (2) Seismic wavelets are quite different due to the continual up-and-down change of surface dunes. (3) The dominant 
frequency of the layer of interest is about $20-25 \mathrm{~Hz}$ (very low). Amplitude-preserved processing for pre-stack inversion in this area is made of five key procedures: 1) $\mathrm{S} / \mathrm{N}$ enhancement including multiples, linear noise, ground waves and random noise attenuation. 2) Consistency improvement. 3) Vertical resolution improvement through deconvolutions in series. 4) Amplitude-preserved pre-stack migration for diffraction and scattering convergence, as well as horizontal resolution improvement. 5) Data conditioning processing after migration. At last, the amplitude versus offset (AVO) anomaly consistency between common reflection point (CRP) gathers and synthetics in the well location is seen as the main quality control standard for amplitude-preserved processing.
The comparison between CRP gathers and synthetics for one well location is shown in Fig. 1. It is shown that their AVO characteristics are similar especially in the target zone marked by the red frame. Apparently, the rationality of the amplitude-preserved processing can be proved. Specifically, a common phenomenon should be noticed is that the near offsets (about less than 1,400 m) of the field data in Ordovician in this area are often contaminated by noise, especially the ground waves. While the far offsets, about deeper than $6,000 \mathrm{~m}$, are always short of reflection information. Therefore, they will bring incorrect information to destroy the inversion result, and should be discarded.

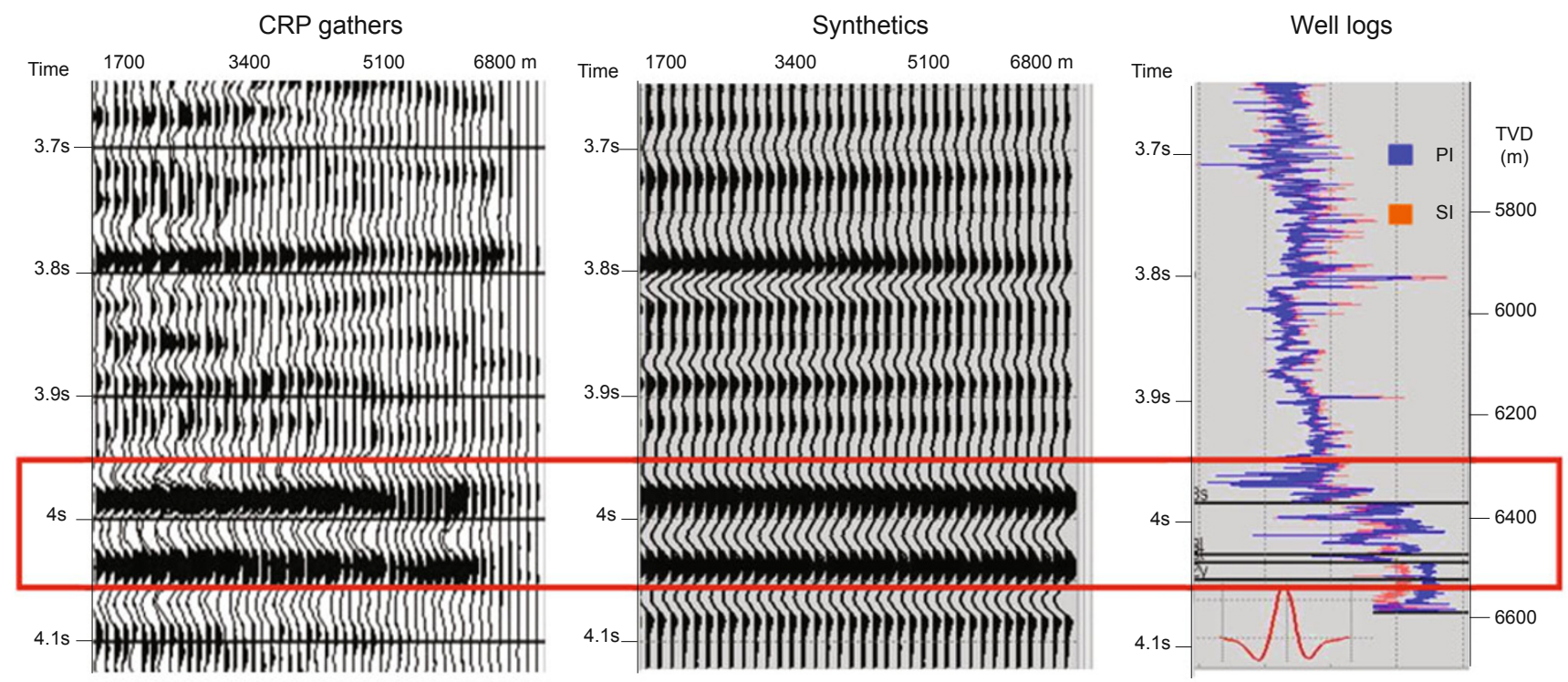

Fig. 1 The comparison between CRP gathers and synthetics

\subsection{Rock-physics analysis}

P-wave velocity $(V \mathrm{p}), \mathrm{S}$-wave velocity $(V \mathrm{~s})$, and density are required for pre-stack inversion. Usually, the combination of $\mathrm{P}$ - and $\mathrm{S}$-wave velocities is more sensitive to reservoir and fluid than that only using P-wave velocity. However, the $\mathrm{S}$-wave velocity is often unavailable in this field. Then rockphysics needs to be employed. Furthermore, it can associate reservoir property and seismic reflection, and can be used to establish the basic criterion for reservoir prediction or fluid identification using pre-stack inversion.

There are some published empirical relationships such as Castagna's mud-rock line and Greenberg-Castagna's $V_{\mathrm{P}}-V_{\mathrm{S}}$ relationship etc (Lamb et al, 1992). However, these equations are built for specific areas and cannot represent all the cases, especially the secondary storage spaces in the Tarim Basin. Specifically, the Kuster-Toksöz Model suitable for the Tarim Basin (Wang et al, 2009) is used for this area in our work.

Fig. 2 shows the cross-plot of P-impedance and $V_{\mathrm{P}}-V_{\mathrm{S}}$ ratio of carbonate layer. The colorful fluid symbols derived from the logging data by fluid substitution in caved carbonate reservoir. It can be seen that no matter the carbonate cave is filled by fluid (oil/gas/water) or mud, the P-impedance (PI) values of carbonate caves are smaller than that of matrix. That is because the compressibility of matrix is stronger than that of mud and fluid. Furthermore, the $V_{\mathrm{P}}-V_{\mathrm{S}}$ ratios of dissolution caves filled by mud are definitely higher than that of fluid-filled ones, since the rigidity of mud is stronger than that of fluid. In a word, the key criterion of heterogeneous carbonate reservoir prediction using AVO inversion is that the $\mathrm{P}$-impedance values of dissolution caves no matter filled with mud or fluid are obviously smaller than that of matrix, and the $V_{\mathrm{P}}-V_{\mathrm{S}}$ ratios of dissolution caves filled by mud are definitely larger than that of fluid-filled ones.

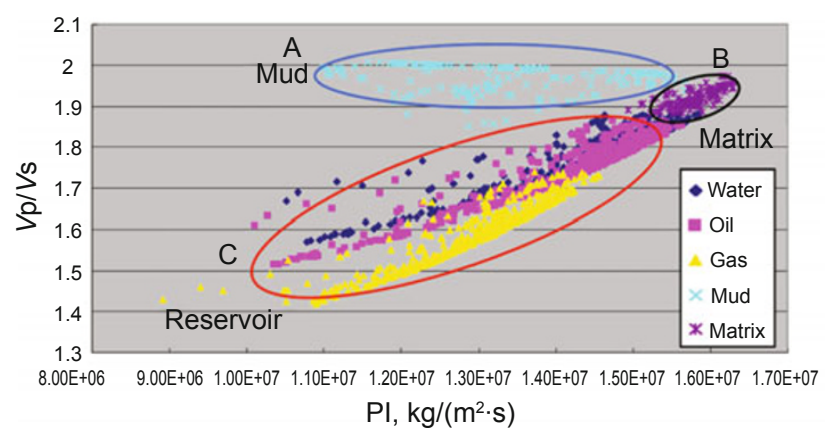

Fig. 2 PI versus $V \mathrm{p} / V \mathrm{~s}$ cross-plot 


\section{Workflow and key procedures of pre-stack} inversion

Pre-stack inversion is better for reservoir prediction than post-stack inversion owing to its preservation of the AVO information and more elastic parameters (Connolly, 1999; Hampson et al, 2005; Li et al, 2008; Shamsa and Lines, 2010). It consists of five major approaches including data preparation, wavelets estimation, low-frequency model building, inversion parameters control and result analysis. The work flow for pre-stack inversion is shown in Fig. 3.

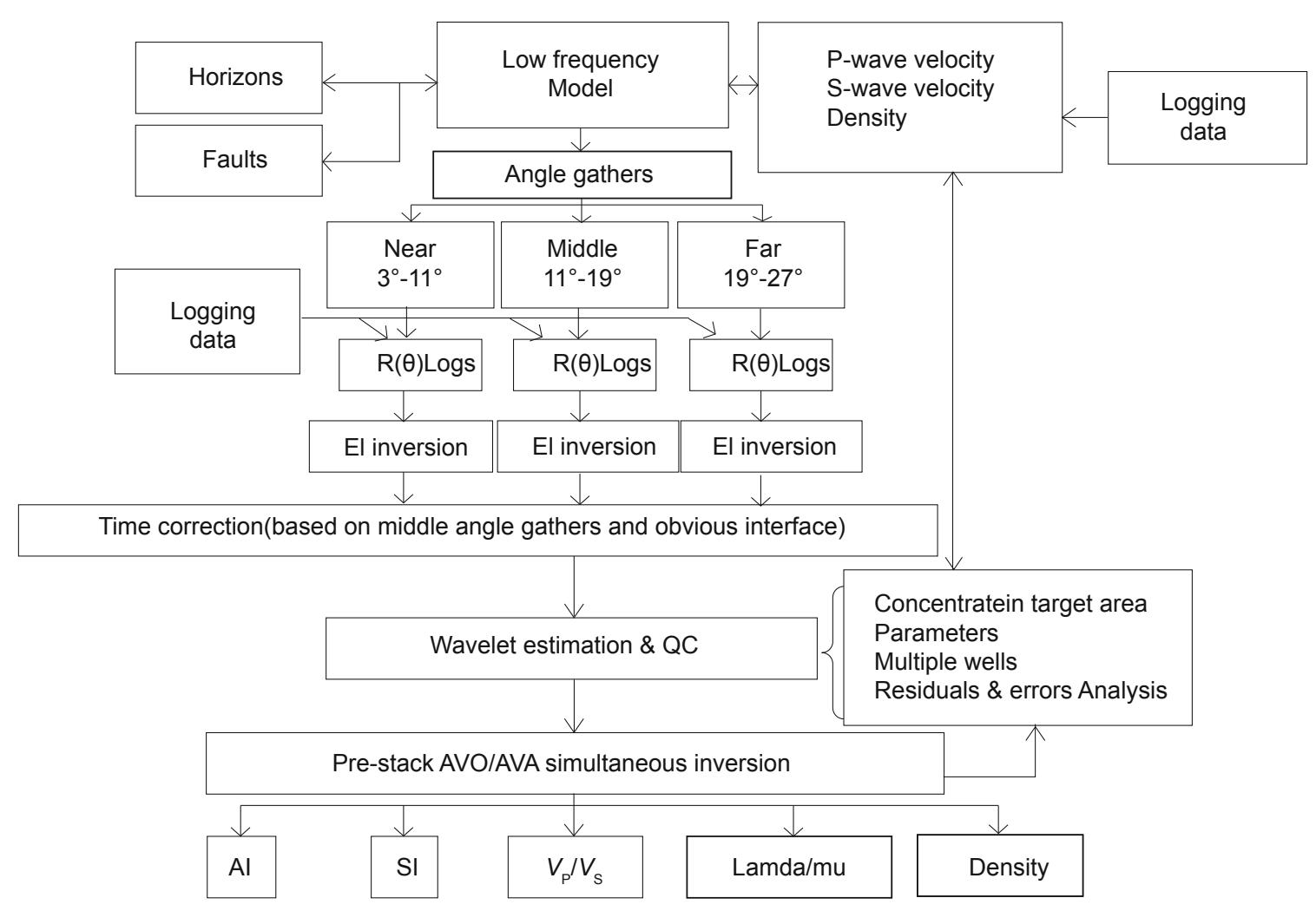

Fig. 3 Workflow of pre-stack seismic inversion

\subsection{Angle gathers conversion and partial angle stack}

The CRP gathers distributed in the offset domain, not suitable for pre-stack inversion, are often converted to angle domain before inversion. For a specific common reflecting point, the incident angle at any offset can be correspondingly computed by a ray-tracing method once the velocity model and relative position of shot and receiver point are known.

Based on the bending ray-tracing method and precise velocity model extracted from pre-stack time migration, the field offset-domain gathers are converted to angle-domain gathers for later partial angle stack in this paper. Firstly, the largest incident angle of target layers and the smallest incident angle influenced by noise should be estimated by integrally analyzing the acquisition feature, burial depth of target layers, as well as noise degree. Secondly, the number of partial stack gathers should be chosen between the largest and smallest incident angle. The largest incidence angle in the carbonate layer in TZ45 area is about $32^{\circ}$, and the near angle data (less than $4^{\circ}$ ) is usually contaminated by noise. Finally, through angle scanning and inversion testing, three angle stacks $\left(4^{\circ}\right.$ $14^{\circ}, 13^{\circ}-23^{\circ}$ and $22^{\circ}-32^{\circ}$ ) for TZ45 area are chosen for AVO inversion.

\subsection{Well-seismic tie and wavelet estimation}

Based on the logging data and geologic horizons, reasonable time-depth relationship should be established to convert the logging data in the depth domain into that in the time domain for wavelet estimation and low-frequency model building in the inversion application. The inversion result is often dominated by wavelet quality since wavelets are the key for inversion computing based on the deconvolution theory. Generally, the amplitude and phase spectra of inversion wavelets are dominated by seismic and logging data respectively. The energy and frequency of wavelets change with distance. In order to reduce the effect of wavelet blemish on inversion, the following processing steps are adopted in this paper: (1) Choosing seismic data processed with zero phases; (2) Estimating those wavelets whose convolutions with well reflectivity series could be the best match with the seismic trace; (3) Diminishing the influence of wavelet change through focusing on the main target layer, and avoiding multi-layer inversion. Following these means above, three angle wavelets close to but not zero-phase are respectively extracted from three stacks and shown in Fig. 4. The energy and frequency of wavelets decrease from near to far. 


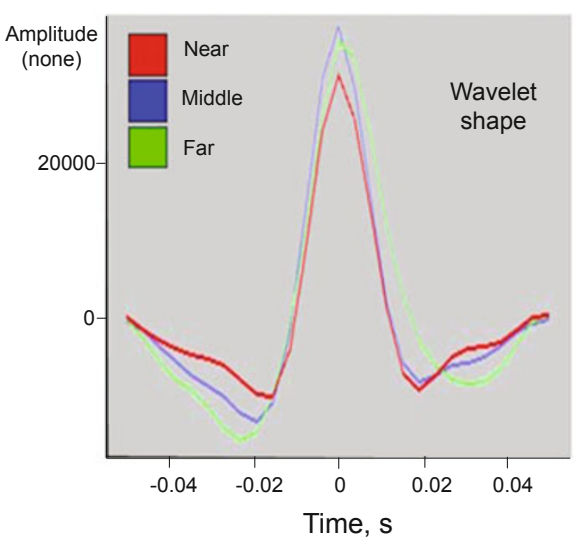

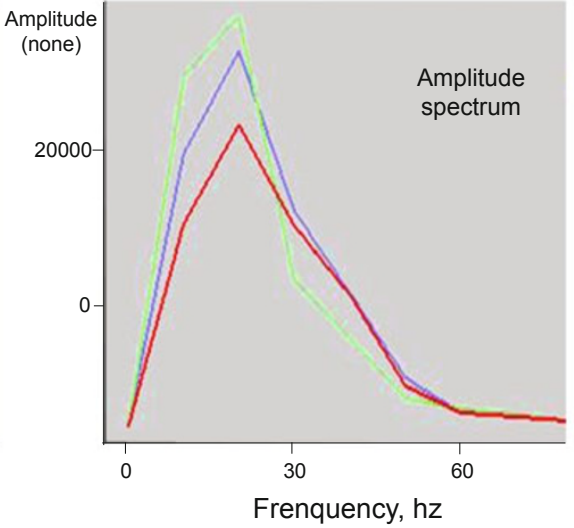

Fig. 4 The last three angle wavelets

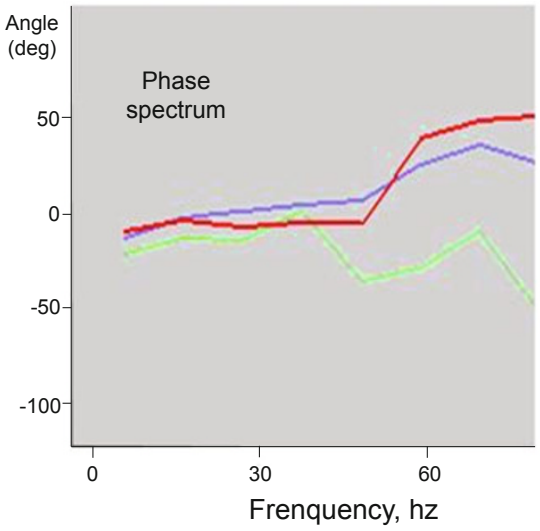

\subsection{Low frequency model building}

Based on precise horizon calibration and structural interpretation, it is a key procedure to build a low frequency model for pre-stack inversion because it can greatly influence the inversion result. In this process, many constrained factors such as geologic horizons, faults, depositional pattern and contact relation of strata should be considered systematically. Integrated with logging data and geology horizons, low frequency models including P-impedance, S-impedance, and density models are built to aid and constrain elastic parameters from reflectivity series in the inversion processing, as well as to supply low frequency information to the inversion result. The structural pattern in this area is simple and it is easy to build a structural framework, but logging quality correction should be conducted before generating models since logging data in dissolution caves are always bad.

\subsection{Inversion residual analysis}

Inversion residual is the difference between original seismic data and synthetics. The best inversion result can be achieved when the residual is random noise since the reflectivity series are made of many strong events stacked in the Gauss background. Inversion residual analysis is an important measure to verify inversion results. Fig. 5 shows the comparison between original data and inversion residual in this area. It is obvious that the residual energy is smaller than seismic data, and rendering as random distributions, which demonstrates the reasonability of pre-stack inversion.

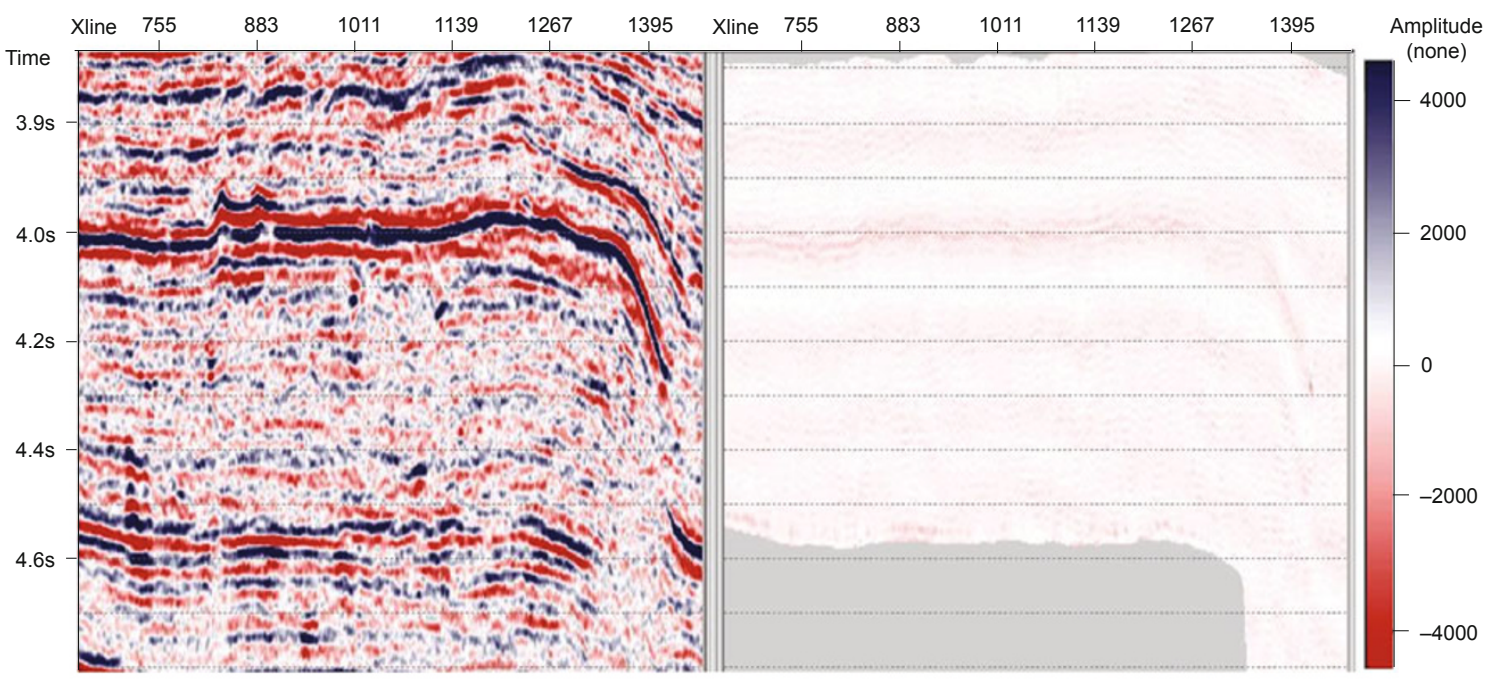

Fig. 5 The comparison between seismic (left) and inversion residual (right) at $13^{\circ}-23^{\circ}$

\section{Inversion result analysis and reservoir prediction}

Because the carbonate matrix is stiffer than the carbonate reservoir, the P-impedance (PI) of the reservoir is significantly lower than that of the matrix. But the S-impedances (SI) between reservoir and matrix are nearly unchanged because reservoir fluid cannot support shear waves. Therefore, the ratio of $V_{\mathrm{P}}$ to $V_{\mathrm{S}}\left(V_{\mathrm{P}} / V_{\mathrm{S}}\right)$ of reservoir is lower compared with that of matrix. Fig. 6 shows the inversion result across the ZG16 well in the study area. It has distinct reservoir inversion characteristics such as low PI, nearly unchanged SI and low $V_{\mathrm{P}} / V_{\mathrm{S}}$ in the area marked by the black ellipse. Actually the reservoir of ZG16 well is a caved carbonate reservoir, and commercial oil production (oil: $180 \mathrm{~m}^{3} / \mathrm{d}$, gas: $50,000 \mathrm{~m}^{3} / \mathrm{d}$ ) is achieved from the reservoir interval of the well. 


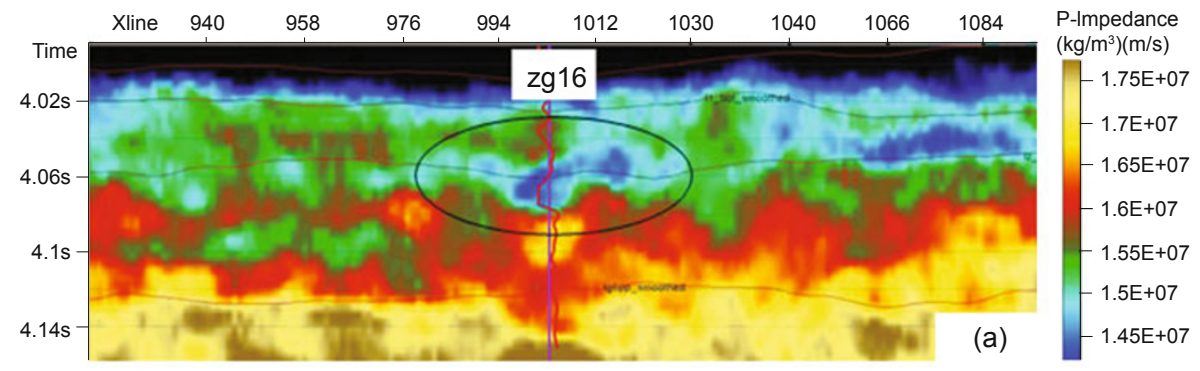

(a)

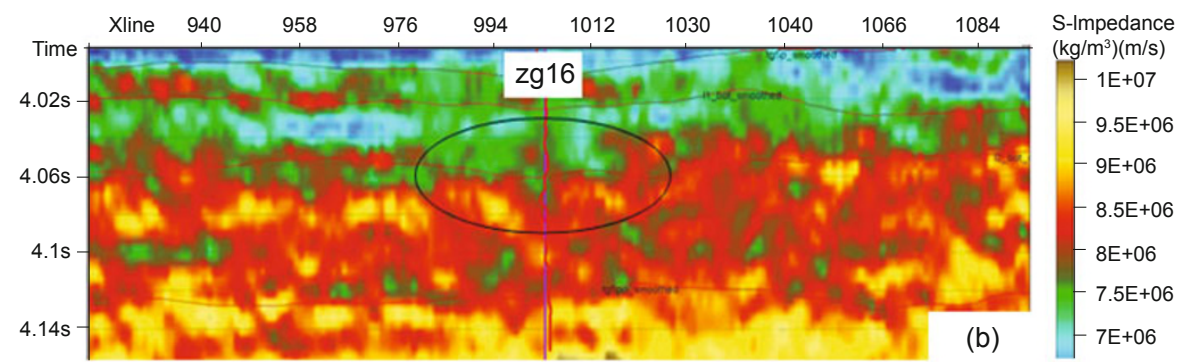

(b)

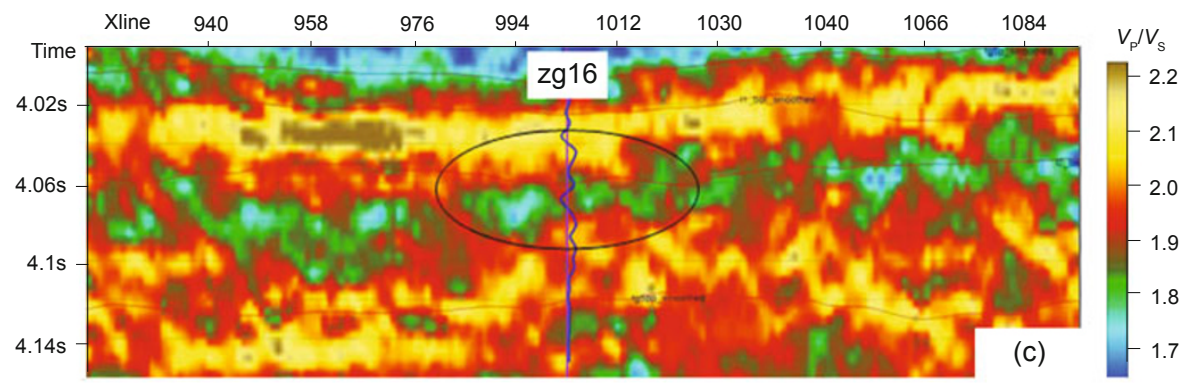

(c)

Fig. 6 Inversion result analysis: (a) P-impedance; (b) S-impedance; (c) $V_{\mathrm{p}} / V_{\mathrm{s}}$

Finally, the distribution of reservoir can be predicted through capturing from inversion result by drawing a polygon similar to the reservoir ellipse in Fig. 2. In this way, the time-thickness of reservoir in the layer of the Lianglitage formationII Ordovician can be computed at last and is shown in Fig. 7, and is further used to analyze the coincident degree with drilling wells. The inversion result is seen as correct (marked by $\checkmark$ ) when the drilling result is consistent well with inversion result, and partially correct (marked by $\nsucc$ ) when the drilling result is partial consistent with the inversion result, and incorrect (marked by $\times$ ) when the drilling result is not consistent with inversion result. As is shown in Table 1, the inversion results are mostly consistent with the oil-testing result. The other instance when the inversion result is not consistent with well data usually presents at the edge of acquisition where we have very poor seismic data and inversion results, or at the area of fractured carbonate reservoir with strong anisotropy which can not be distinguished by our isotropic inversion method. However, the reservoir distribution predicted by pre-stack inversion can provide a significant guide for future well-drilling.

Table 1 The comparison of the predicted reservoir distribution and oil-testing results

\begin{tabular}{ccccc}
\hline Wells & Oil production /day & Gas production /day & Oil test results & Inversion result \\
\hline TZ451 & $361 \mathrm{~m}^{3}$ & $282249 \mathrm{~m}^{3}$ & Hydrocarbon zone & $\checkmark$ \\
TZ45 & $300 \mathrm{~m}^{3}$ & $111548 \mathrm{~m}^{3}$ & Hydrocarbon zone & $\checkmark$ \\
TZ86 & $42.3 \mathrm{~m}^{3}$ & $8755 \mathrm{~m}^{3}$ & Hydrocarbon zone & $\checkmark$ \\
ZG16 & $180 \mathrm{~m}^{3}$ & $50000 \mathrm{~m}^{3}$ & Hydrocarbon zone & $\checkmark$ \\
TZ63 & $/$ & $/$ & Hydrocarbon show & $\checkmark$ \\
ZG18 & $/$ & $/$ & Hydrocarbon show & $\checkmark$ \\
TZ88 & $/$ & $/$ & Non-reservoir & $\checkmark$ \\
TZ452 & $/$ & $/$ & Non-reservoir & $\checkmark$ \\
\hline
\end{tabular}




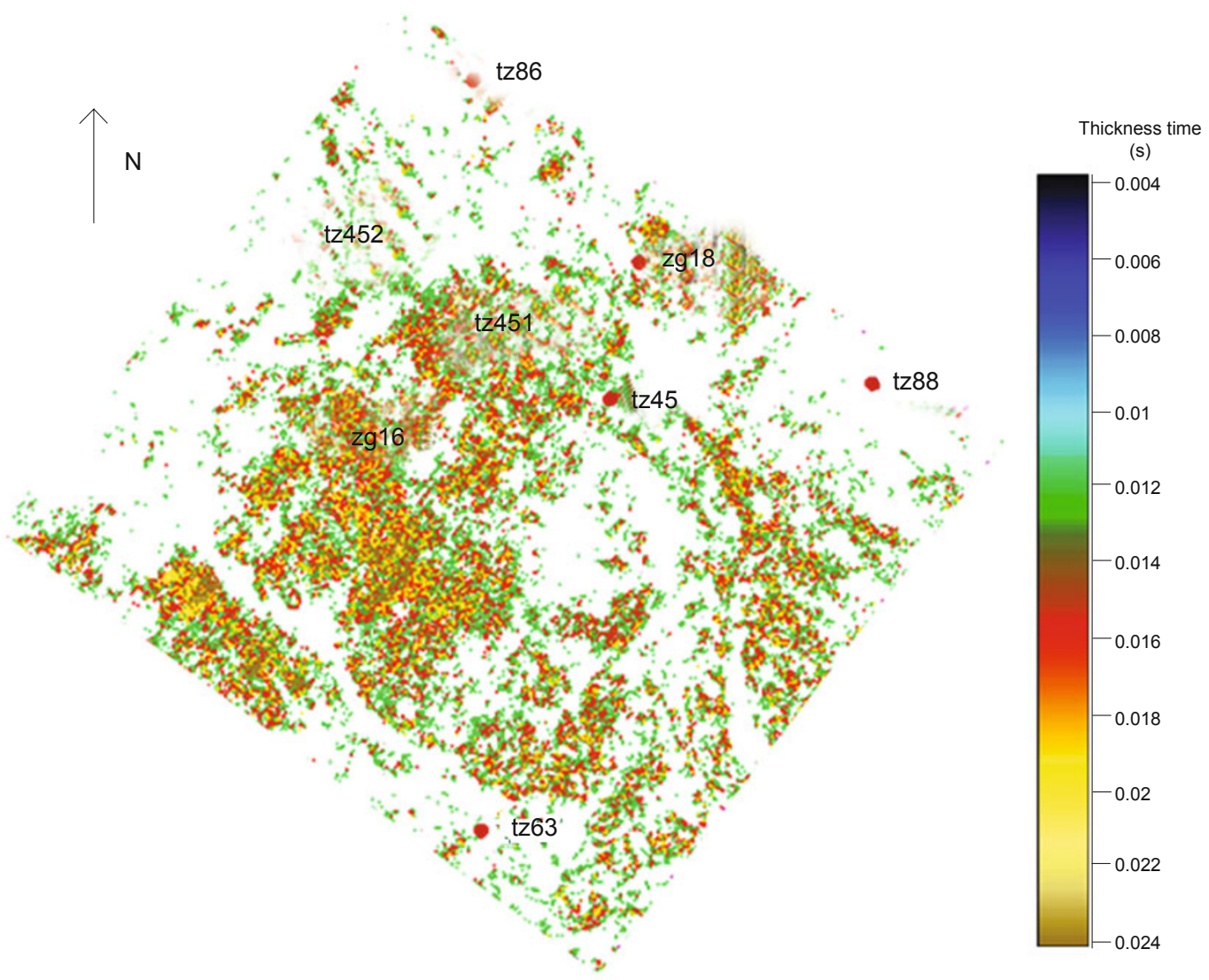

Fig. 7 The predicted reservoir distribution in the study area

\section{Conclusions}

It is confirmed that based on amplitude-preserved data processing and rock-physics analysis, integrated with kinds of geology situations, combined with careful quality control in each inversion stage, pre-stack inversion can be well applied for caved carbonate reservoir prediction. Besides, the degree of consistency between seismic gathers used for pre-stack inversion and synthetics should be seen as the major quality -control factor.

\section{Acknowledgements}

The work is supported by National Basic Research Program (2006CB202304) of China, and co-supported by the National Basic Research Program of China (Grant No. 2011CB201103) and the National Science and Technology Major Project of China (Grant No. 2011ZX05004003). The authors would like to thank the Lab for Integration of Geology and Geophysics (LIGG) at China University of Petroleum for the permission to publish this work and Tarim Oilfield Co., PetroChina for their help in providing field data.

\section{Reference}

Cai R. Carbonate cave identification by using a spectral decomposition technique. Petroleum exploration and development. 2005. 32(2): 8285 (in Chinese)

Chen G P, Pan J G and Tao Y G. The application of multiple information for predictive of carbonate karst reservoir and effect analysis.
Geophysical prospecting for petroleum. 2005. 44(1): 33-36 (in Chinese)

Connolly P. Elastic impedance. The Leading Edge. 1999 (18). 438-452

Gong H L, Wang Z Q, Li L M and Cai G. Predicting carbonate reservoir by applying seismic spectral decomposition technique. Progress in geophysics. 2008. 23(1): 129-135 (in Chinese)

Hampson D P, Russell B H and Bankhead B. Simultaneous inversion of pre-stack seismic data. 75th SEG Expanded Abstract. 2005. 16331637

Lamb W J, Zhu X H, et al. Elastic wave propagation in composite media. Geophysics. 1992. 57: 1155-1165

Li H B, Cui X F and Huang W F. Stack impedance. 78th SEG Expanded Abstract. 2008. 2021-2025

Li Y Y and Downton J. The applications of amplitude versus offset in carbonate reservoirs: re-examining the potential. 70th SEG Expanded Abstract. 2000. 166-169

Liu L F, Li Y, Wang P, et al. Reservoir types and favorable oil-gas exploration zone prediction of the Upper Ordovician Lianglitage Formation in Tazhong No 1 fault belt of Tarim Basin. Journal of Palaegeography. 2008. 10(3): 221-229 (in Chinese)

Pang X Q, Zhou X Y, Lin C S, et al. Classification of complex reservoirs in superimposed basins of Western China. ACTA GEOLOGICA SINICA (English Edition). 2010. 84(5): 1011-1034

Shamsa A and Lines L. A case study in the application of inversion methods to a Persian Gulf reservoir. 80th SEG Expanded Abstract. 2010. 2896-2900

Wang H Y, Sun Z D and Yang H J. Velocity prediction models evaluation and permeability prediction for fractured and caved carbonate reservoir: from theory to case study. 79th SEG Expanded Abstract. 2009. 2194-2198

Wu G H, Li Q M, Zhang B S, et al. Structural characteristics and 
exploration fields of No.1 faulted slope break in Tazhong area. Acta Petrolei Sinica. 2005. 26(1): 27-30 (in Chinese)

Yang H J, Wen Q P, Chen L X, et al. Seismic description of karst topography and caves of Ordovician carbonate reservoirs, Lungu area, Tarim Basin, West China. 80th SEG Expanded Abstract. 2010. 1256-1260

Yang P, Liu Y L, Hou Y P, et al. Carbonate-reservoirs prediction strategy and technologies in Tarim Basin of China. 77th SEG Expanded Abstract. 2007. 2738-2742

Zeng H L, Wang G Z, Janson X, et al. Characterizing seismic bright spots in deeply buried, Ordovician Paleokarst strata, Central Tabei uplift, Tarim Basin, Western China. Geophysics. 2011. 127-137

Zhang H, Zheng J M, Yang D Q, et al. Prediction of paleokarst reservoir in the southeastern slope of Tazhong area in Tarim Basin using seismic techniques. Acta Petrolei Sinica. 2008. 29(1): 69-73 (in Chinese)

Zhao Z J, Wang Z M, Wu X N, et al. Genetic types and distribution forecast of available carbonate reservoirs in Ordovician in the central area of Tarim Basin. Petroleum Geology \& Experiment. 2007. 29(1): 40-46 (in Chinese)

(Edited by Zhu Xiuqin) 